\title{
O ENSINO DE GEOGRAFIA NA PANDEMIA COVID-19: UMA ANÁLISE DA PERSPECTIVA DO LUGAR ATRAVÉS DE HISTÓRIAS EM QUADRINHOS PELOS ALUNOS DA ESCOLA MUNICIPAL DE ENSINO FUNDAMENTAL PROF $^{\text {a }}$ CÂNDIDA ZASSO DE NOVA PALMA-RS ${ }^{1}$
}

\author{
TEACHING GEOGRAPHY IN PANDEMIA COVID-19: AN ANALYSIS OF THE \\ PERSPECTIVE OF THE PLACE THROUGH HISTORICAL STORIES BY \\ STUDENTS AT THE MUNICIPAL SCHOOL OF FUNDAMENTAL \\ PROFESSIONAL EDUCATION. CÂNDIDA ZASSO DE NOVA PALMA-RS
}

\section{Vanessa Manfio ${ }^{2}$}

\section{RESUMO}

O ensino de Geografia procura integrar o espaço e o mundo vivido, abordando o cotidiano e a realidade por meio de atividades que fortaleçam a participação dos alunos na busca pela construção do conhecimento educacional. Nestes tempos difíceis, de Pandemia, cujo isolamento social impôs o fechamento das escolas, para preservar o bem-estar da comunidade escolar, é fundamental propor metodologias ativas como a criação de histórias em quadrinhos, onde os educandos têm a oportunidade de expor suas experiências, entendendo o lugar e a realidade de vida, vislumbrando as articulações que a Geografia apresenta como uma ciência complexa. Por isso, este artigo propôs o diálogo a respeito da prática de ensino aplicada com os alunos do sexto ano do ensino fundamental em junho de 2020, na escola Municipal de Educação Fundamental Cândida Zasso, objetivando trabalhar de forma mais criativa com os alunos, a partir de atividades remotas, pautadas no método construtivista. Em síntese, o estudo prevê uma contribuição no ensino de geografia, especialmente em tempos de adversidade.

Palavras-chave: Ensino remoto, Geografia Escolar, histórias em quadrinhos, lugar e realidade.

\section{ABSTRACT}

Geography teaching seeks to integrate space and the world experienced, addressing daily life and reality through activities that strengthen student participation in the search for the construction of educational knowledge. In these difficult times, of Pandemia, whose social isolation imposed the closure of schools, to preserve the wellbeing of the school community, it is essential to propose active methodologies such as the creation of comic books, where students have the opportunity to expose their experiences, understanding the place and the reality of life, glimpsing the articulations that Geography presents as a complex science. For this reason, this article proposed a dialogue regarding the practice of applied teaching with students of the sixth year of elementary school in June 2020, at the Municipal School of Fundamental Education Cândida Zasso, aiming to work more creatively with students, starting from remote activities, based on the constructivist method. In summary, the study foresees a contribution to the teaching of geography, especially in times of adversity.

Keywords: Remote teaching, School Geography, comic stories, place and reality.

\footnotetext{
${ }^{1}$ Trabalho de prática escolar.

${ }^{2}$ Licenciada em Geografia Plena, Mestre e Doutora em Geografia. Pesquisadora do Núcleo de Estudos Agrários da Universidade Federal do Rio Grande do Sul (UFRGS). E-mail: nessamanfio@gmail.com
} 


\section{INTRODUÇÃO}

A Geografia escolar tem um papel muito significativo na formação dos educandos, ajudando-os a pensar sobre o seu espaço vivido, sobre a realidade e o cotidiano. A Geografia se encontra na beleza do vento, no encontro da natureza com a sociedade e na efervescência do movimento diária da vida urbana e rural. É uma ciência que se relaciona com as demais, que está nas pequenas coisas e nos grandes acontecimentos. Por isso, ensinar geografia em sala de aula requer abrir mão do quadro e do livro didático e se aventurar para outros limiares, o da literatura, das práticas, do trabalho de campo, da exposição do aluno, das atividades lúdicas. Mas, como ensinar de forma atrativa e diversa em tempos onde os alunos não podem sair de casa? Como fazer os educandos perceber a sua experiência cotidiana no lugar geográfico?

Tentando atender estas inquietações, buscou-se trabalhar com os alunos o conteúdo do lugar e cotidiano em tempos de Pandemia, a partir do ensino do conceito de lugar e cotidiano e da criação de Histórias em Quadrinhos (HQ). A constituição de histórias em quadrinhos pelos alunos permite que os mesmos demonstrem os seus conhecimentos sobre o conteúdo, e a sua percepção sobre a vida, nestes tempos de isolamento social, provocados pela Pandemia do Covid-19 que atingiu o mundo todo. Essa prática pedagógica foi trabalhada com os alunos do $6^{\circ}$ ano do Ensino Fundamental da Escola Municipal de Ensino Fundamental Professora Cândida Zasso, localizada no município de Nova Palma, no centro do Rio Grande do Sul. A escola apresenta uma infraestrutura e um quadro de profissionais que versam pelas práticas pedagógicas construtivistas.

Para a prática pedagógica foi utilizado o método construtivista. Este considera que o professor não é o único que tem acesso aos conteúdos da disciplina, ou seja, o aluno também possui conhecimentos e meios para acessar o conteúdo e se tornar ativo no processo de ensino-aprendizagem (CHAHUÁN-JIMÉNEZ, 2009). O método construtivista vai de encontro ao que Paulo Freire considera do ensino, a partir da liberdade, da prática e da construção de ensino. O ensino pauta-se no diálogo entre o professor e o aluno, no qual o educador não é apenas o que educa, ao mesmo tempo em que educa o aluno, ele também é educado (FREIRE, 1978). Dessa forma, é fundamental dar voz e vez ao aluno no seu aprendizado, especialmente ao tratar da realidade do educando.

Portanto, este artigo busca contribuir com as discussões sobre o ensino de Geografia, dialogando sobre a educação, nestes tempos de Pandemia, onde a distância física entre aluno e professor se ameniza pelo contato virtual, pela interface do computador através de atividades remotas que orientam a continuidade dos estudos e aprendizados iniciados, anteriormente a COVID-19, e abre portas para no pós-pandemia os encontros educacionais continuarem sendo trilhados valorizando as metodologias ativas. 


\section{A EDUCAÇÃO NA PANDEMIA A PARTIR DE ATIVIDADES REMOTAS}

A educação é um pilar da formação intelectual, pessoal e social. Ela é construída por constantes trocas entre os indivíduos, conteúdos e ambientes. Para Libâneo (2013), a educação é toda modalidade de influências e inter-relações que convergem para formação de traços de personalidade e ações frente à realidade como o desenvolvimento cognitivo e moral. A educação escolar, por sua vez, tem como vínculos ativos a integração do aluno/professor, buscando atingir o aprendizado por meio de saberes científicos, estímulo do olhar e curiosidade do alunado em abrir-se para o conhecimento.

A educação básica é feita através de aulas, tipicamente presenciais, numa construção diária e com múltiplas metodologias, atendendo a diversidade de alunos que compõe uma classe escolar - especialmente no ensino moderno/atual que valoriza o sujeito e sua aprendizagem. Este ensino é ofertado por escolas públicas e privadas.

Como dito anteriormente, a educação não acontece por meio de um único indivíduo e sim na comunhão humana. No entanto, com a Pandemia do COVID-19, que afetou a educação com o fechamento das escolas, as aulas presenciais foram substituídas por aulas remotas, ou seja, um ensino que não é considerado Educação à Distância, para alguns autores, pois nem os professores, tão pouco os alunos e o currículo estão alinhados neste ensino. Porém, muitas das críticas se escondem no horizonte pós-pandemia de revisão se os materiais utilizados virtualmente na educação remota: o EaD, o homeschooling, o acesso à educação via canais sociais permanecerão como instrumento didático (RAVITCH, 2020, apud FRANÇA FILHO; ANTUNES; COUTO, 2020). O que se tem certeza é que o ensino precisa mudar, sair do tradicionalismo, mas a interação diária entre professor e aluno, a presença física na escola é fundamental nesta construção, especialmente na educação básica. E neste contexto, as tecnologias podem sim ser um pano de fundo para contribuir com o ensino, como um acessório.

Sabe-se que na educação remota, algumas escolas adotaram plataformas de ensino, canais de comunicação diversos, outras transformaram o WhatsApp, o site da escola, o email em meios de interação entre professores e alunos para o fornecimento de atividades, aulas e orientações aos jovens estudantes. É uma maneira de não romper com a educação escolar neste momento de isolamento social e preservar o ano letivo. Segundo Arruda (2020, p. 266), "a educação remota é um princípio importante para manter o vínculo entre estudantes, professores e demais profissionais da Educação". E se bem elaborada, esse ensino pode minimizar a crise da Pandemia de Covid-19 na educação escolar e se tornar uma janela de oportunidades para uso da tecnologia como ferramentas educacionais.

Portanto, ensinar em ambientes digitais e interativos supõe: organizar situações de aprendizagem, planejar e propor atividades; disponibilizar materiais de apoio e ter um professor como mediador do aluno (ALMEIDA, 2003), tal qual na pandemia os pais e familiares têm sido o intermediador entre professor e aluno no ensino básico, especialmente de alfabetização escolar. É neste caminho, que a 
educação remota vem se organizando, viabilizando práticas para o ensinamento das disciplinas, a partir de recursos virtuais e das trocas online entre aluno/professor.

Além disso, a educação nesse quadro de isolamento social vem superando muitos desafios, tais quais: as desigualdades digitais, a falta de domínio tecnológico de alguns docentes, a dificuldade de avaliação escolar, a rotina escolar em casa dos alunos, entre outros. Um dos grandes desafios da educação e especialmente da Geografia escolar é romper com a decoreba de conceitos e temas. Como aponta Santana Filho (2020) que nas aulas de Geografia poderiam prevalecer à compreensão da dinâmica global da disseminação do vírus, da relação com a cadeia produtiva e de circulação de bens, mercadorias e pessoas, da circulação controlada. Neste molde, muitos colegas da Geografia estão tentando inserir a realidade de vida nas aulas. É fundamental como ciência trabalhar o cotidiano do aluno, especialmente quando o assunto deixa a todos paralisados. Isto promove a reinvenção do docente, protagonizando novas formas de ensino, buscando a partir do lúdico e da criatividade manter o interesse e o ensino para além da escola.

Desse modo, o docente tem trabalhado exaustivamente em lives, produção de vídeos, aulas, conteúdos interativo, correção e auxílio aos alunos, superando a carga horária presencial. Muitos professores não têm mais uma rotina e nem tempo programada para as suas aulas, pois a docência está na casa, o Home Office, ou seja, trabalho remoto em casa e, com isto, amplia-se o atendimento ao aluno. É um desafio que outras profissões estão enfrentando também, a separação entre lazer e trabalho, já que o virtual protagoniza vários eventos. Ademais, os professores participam frequentemente de cursos de capacitação nas plataformas digitais, a fim de saber lidar com a educação nesta nova realidade de vida social.

Em suma, o ensino-aprendizagem ganha uma nova roupagem, uma educação mais interativa e também menos intensa, que tem como objetivo básico trabalhar com os conteúdos de forma a envolver o aluno, a pensar em si e no outro, a vivenciar o lugar e a realidade, a superar as angústias e a desenvolver trabalhos manuais que os orientem na compreensão do conteúdo escolar, mas ainda dos anseios e das expectativas pós-pandemia. E, para isto, a educação tem um papel essencial, construir mentes abertas ao pensamento, mentes criativas ao novo e a superar de nostalgias deste mundo pandêmico.

\section{A GEOGRAFIA, O LUGAR E O ENSINO REMOTO: UMA PROPOSTA DE TRABALHO COM HISTÓRIA EM QUADRINHOS}

Partindo da ideia que "a escola deva ser um espaço de investigação da realidade e da construção dos instrumentos necessários ao seu entendimento" (FRANÇA FILHO; ANTUNES; COUTO, 2020, p. 29). A escola não pode se retrair no tratamento da Pandemia do Covid-19 que vem afetando o mundo inteiro, principalmente com o isolamento social e a alta carga de contaminação do vírus. Para dar conta desta problemática com os alunos, muitas disciplinas estão relacionando seus conteúdos com a Pandemia, entre eles, a Biologia, a Educação Física, e a Geografia. 
A Geografia tem uma relação intrínseca com o diálogo do lugar e do cotidiano, sendo uma de suas vertentes pedagógicas o trabalho com esta temática. Como afirma Kaercher (1998), é preciso exercitar os alunos a ler, escrever e dizer suas palavras sobre o mundo a partir de suas realidades. Completa Freire (1999, p. 44) que "a localidade dos educandos é o ponto de partida para o conhecimento que eles vão criando do mundo". Logo, estudar a realidade conhecida pelos alunos é um agente facilitador no processo de aprendizagem, instigando os mesmos a refletir sobre o meio que estão inseridos (CASTELLAR, 2000). É importante fazer os alunos entender o lugar, a realidade diária para depois adentrar a Geografia das coisas e da globalidade.

O lugar é mais que um ponto de referência, de localização geográfica. Para a Geografia humanista o lugar envolve as subjetividades da experiência humana, o pertencimento, a segurança e afetividade, o seu lugar no mundo (TUAN, 1983). "Essa perspectiva geográfica vê no lugar o espaço que é familiar, vivido, experienciado" (OLIVEIRA; RODRIGUES, 2018, p. 144). Em contrapartida, Santos (2009, p. 314), expressa que "os lugares (...) podem ser vistos como um intermédio entre o mundo e o Indivíduo [...], cada lugar é a sua maneira o mundo". Logo, Oliveira e Rodrigues (2018, p. 139), dizem que "O lugar não é um ponto definido por coordenadas geográficas, [...] uma localização física ou uma representação cartográfica; ele é a articulação da espacialidade com as relações sociais estabelecidas entre seres humanos e os elementos que compõem esse espaço”. O lugar é o ponto inicial para analisar a sociedade e o meio. Para Callai (2000, p. 72),

Compreender o lugar em que vive permite ao sujeito conhecer a sua história e conseguir entender as coisas que ali acontecem. Nenhum lugar é neutro, pelo contrário, é repleto de história e com pessoas historicamente situadas em um espaço maior, mas por hipótese alguma é isolado, independentemente.

E na visão da experiência, Tuan (1983, p. 10), coloca que

\begin{abstract}
A experiência implica a capacidade de aprender a partir da própria vivência. Experienciar é aprender; significa atuar sobre o dado e criar a partir dele. $O$ dado não pode ser conhecido em sua essência. O que pode ser conhecido é uma realidade que é um constructo da experiência, uma criação de sentimento e pensamento.
\end{abstract}

Nesta linha, o cotidiano permite a compreensão do lugar, pois tende a demonstrara capacidade de acontecimentos e fenômenos, a vida da cidade, a vida do campo, a vivência no dia-a-dia por meio da relação sociedade e natureza (CALLAI, 2000). O cotidiano é a experiência diária, o fazer de ontem, hoje e amanhã (SANTOS, 1996). O cotidiano é importante, pois inspira o pensar da Geografia física e humana, ou seja, demonstra as horizontalidades e verticalidades dos fenômenos que acontecem no espaço localmente em relação à realidade e a complementaridade das experiências. Partindo destes conceitos fundamentais na Geografia escolar e avaliando a condição da Pandemia na vida dos alunos e na educação é necessário pensar em metodologias, atividades e práticas para os alunos 
demonstrarem seu conhecimento e vivência. Neste ponto, utilizou-se a construção em histórias em quadrinhos para que os educandos explorarem o seu lugar e vivência na Pandemia.

As histórias em quadrinhos serão um legado também para demonstrar a história da educação, neste tempo de Pandemia, é importante deixar registros sobre o ensino e a percepção dos alunos sobre a realidade e lugar. Certamente a educação remota será uma aprendizagem para uma futura superar de obstáculos e lacunas da educação, especialmente em tempos de Pandemia. Neste momento, a educação precisa buscar entreter e manter o vínculo dos alunos com a escola, assim como manter a construção educacional que havia se iniciado anteriormente a COVID-19. Não significa que é o mesmo aprendizado, mas uma construção para evitar os afastamentos escolares e manter a formação intelectual dos alunos.

Sobre as histórias em quadrinhos, Neves e Rubira (2017) afirmam que elas, mesmo com as tecnologias continuam em "alta", revelando a sua importância nas contribuições na educação, oferecendo aos alunos uma leitura do espaço geográfico de uma maneira lúdica e criativa, a partir da literatura e na arte. Desse modo, "Os quadrinhos constituem fonte de pesquisa por representarem diferentes ambientes e possuírem, também, valor de conhecimento expresso, não devendo ser, portanto, simplesmente ignorados na pesquisa em Geografia” (MENDONÇA; REIS, 2015, p. 99).

A partir das histórias em quadrinhos prontas ou criadas pelos alunos pode ocorrer a sistematização do conhecimento geográfico. Existem várias tirinhas e histórias que tratam do meio ambiente, do campo, da cidade, a globalização e fornecem uma leitura importante para o aprendizado dos conteúdos estudados em sala de aula. Além disso, elas são um suporte para o aluno mostrar a sua opinião e o seu aprendizado sobre os assuntos já abordados em aula anteriormente. Assim, mostram a realidade de vida das pessoas e do seu espaço vivido e da experiência cotidiana. Portanto, a Geografia, tais quais as outras disciplinas, precisam destacar o ensino com atividades mais atrativas e cativantes. Neste ponto,

[...] as HQs surgem como um dos recursos com imenso potencial pedagógico capaz de articular-se aos vários campos do conhecimento, propiciando uma forma de expressão da comunicação artística e literária atual, em que é possível relacionar as vivências e experiências do educando com o contexto teórico. (MELO; MEDEIROS; SILVA, 2013, p. 267).

Para Rama (2007, p. 88), “além de explorar os temas específicos tratados nas histórias, é possível também trabalhar com a linguagem dos quadrinhos para ensinar alguns conceitos da Geografia, tais como representação do espaço, escala, visão vertical e oblíqua, leitura de símbolos”. Dessa forma, os quadrinhos e histórias fornecem dados de representação, percepção e orientação, trazendo o aluno para dentro do universo do ensino de Geografia.

Contudo, a união entre a experiência da Pandemia, a Geografia escolar e as histórias em quadrinhos pode contribuir para trabalhar o imaginário, o real, o lugar e o sentimental dos alunos, de uma maneira diferente, orientando-os a explorar a sua concepção, percepção e sentimentos sobre o momento vivido, no contexto do lugar, principalmente porque o mesmo virou o espaço de referência, 
do trabalho, do ensino, do lazer, do habitar e do relacionar. Na atualidade a casa está com múltiplasdimensões. Uma destas é a dimensão escolar, pois a escola insere-se no ambiente da morada e o aluno perde aquele espaço educativo de vivências e trocas com os colegas, e, muitas vezes, a rotina do estudo diário. Isto resulta num misto de emoções aos alunos, incidindo no aprendizado do educando.

\section{AS HISTÓRIAS EM QUADRINHOS E O CONTEXTO DO LUGAR NA PANDEMIA: UMA EXPERIÊNCIA DA ABORDAGEM DA GEOGRAFIA ESCOLAR}

O lugar é um dos conceitos trabalhados com os alunos do $6^{\circ}$ Ano do Ensino Fundamental, buscando inserir o aluno ao entendimento do seu entorno, da sua vivência, para mais tarde trabalhar outros conteúdos. A Geografia Escolar se debruça neste conceito, pois permite explorar os conhecimentos prévios dos alunos e suas expectativas. Ao abordar o lugar e o vivido de forma diferente contemplando a realidade da vida na Pandemia do COVID-19 foi organizada a aula remota partindo de uma breve explicação com a utilização de vídeos, historinha e PowerPoint sobre o lugar e a vivência, introduzindo o conceito aos educandos.

Num primeiro momento foi trabalhado com o conceito de lugar e cotidiano a partir de textos, histórias literárias e exercícios, material oferecido aos alunos via Whatsapp que é o canal de encontro entre professor e aluno, utilizado pela Escola Municipal de Ensino Fundamental Professora Cândida Zasso. Nesse momento, foram tecidos os aprendizados sobre os conceitos e sobre a realidade de vida dos alunos.

No segundo momento, tentando contemplar o lugar e a vivência, dando voz aos alunos explorarem sua experiência na Pandemia em seu lugar foi instigado aos alunos de desenvolverem uma história em quadrinhos, destacando suas atividades, angústias, e relações. Os alunos ficaram livres para fazer quantos quadrinhos eles julgavam ser fundamentais para mostrar o cotidiano, bem como do material a ser usado na produção da história. Os alunos tiveram duas semanas para expor seus conhecimentos e criar sua história.

A atividade pode contemplar a criatividade dos alunos e o seu conhecimento adquirido. Ainda, a atividade demonstrou que a maioria dos alunos está ansiosa pela volta das aulas e do encontro social, ou seja, pelo fim da Pandemia (figura 1 e 2). Muitos alunos moram com os pais e os avôs ou próximos deles, dessa forma, ainda mantêm um convívio familiar mais aberto, que se estende ao contato com os avôs. Mas, a falta de relação com os amigos é uma dificuldade sensível aos discentes.

Os alunos relataram que neste período estão fazendo atividades da escola, ajudando em casa nas atividades domésticas, assistindo televisão, entre outros atrativos. Os alunos que moram no interior têm um ambiente com atividades manuais e uma riqueza natural que lhes permitem o contato com o verde, com os animais, com a terra, enquanto os alunos da cidade a casa é o ponto central da vida em Pandemia. 
Nas histórias em quadrinhos, também ficou clara a presença da casa, dos animais e flores. Além da mensagem de esperança, que finaliza todas as histórias, sinalizando o otimismo dos alunos em um novo começo, após a pandemia. Certamente a atividade foi um momento de expor os seus sentimentos e vivência, a expectativa do aluno como telespectador de uma Pandemia. Estas atividades ajudam os alunos na percepção e na concepção de mundo vivido, pautado na realidade diária que se perpetua nos tempos de isolamento social.

Além disso, a construção de histórias em quadrinhos são documentos importantes que no futuro serão parte da história da educação nos tempos de Pandemia. É um marco de como os alunos analisaram o cotidiano. É muito importante traçar propostas pedagógicas que facilitam o aprendizado do educando e a sua articulação com a realidade de vida.

Figura 1 - História em quadrinhos sobre o lugar na Pandemia

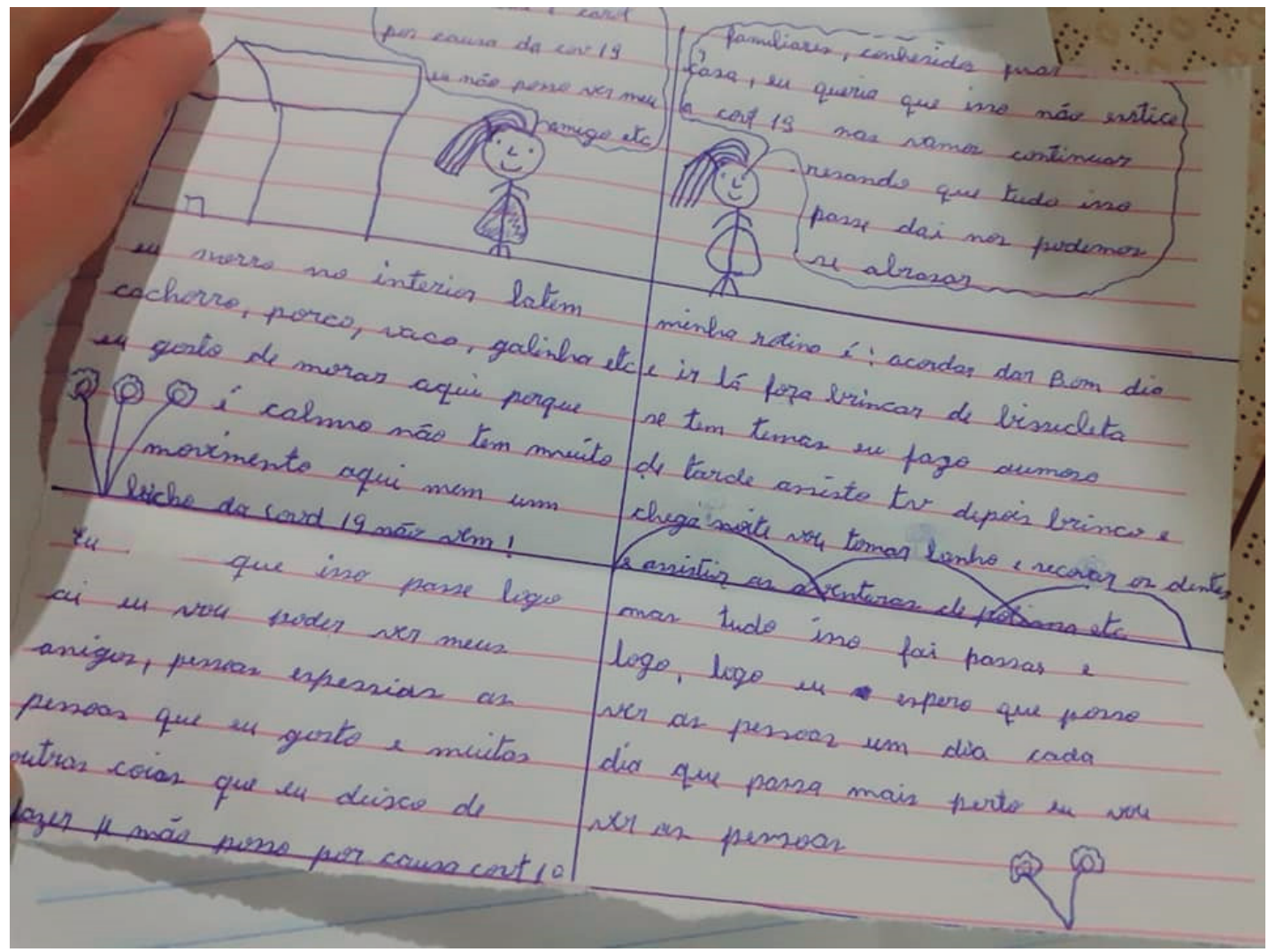

Fonte: HQ criada pelo aluno A.

$\mathrm{Na}$ figura 2, o educando expressa na história em quadrinhos os cuidados com a higiene, neste período, o uso de máscaras na menina que sai para rua, o vidro de álcool em gel, demonstrando uma percepção dos alunos quanto aos cuidados de isolamento e transmissão do COVID-19, fruto da orientação familiar, escolar e das campanhas publicitárias. É importante observar que os alunos mantêm uma visão sobre estes pontos também e a relação deles com o lugar. 
Figura 2 - Trabalho desenvolvido por aluno sobre Lugar e experiências diárias

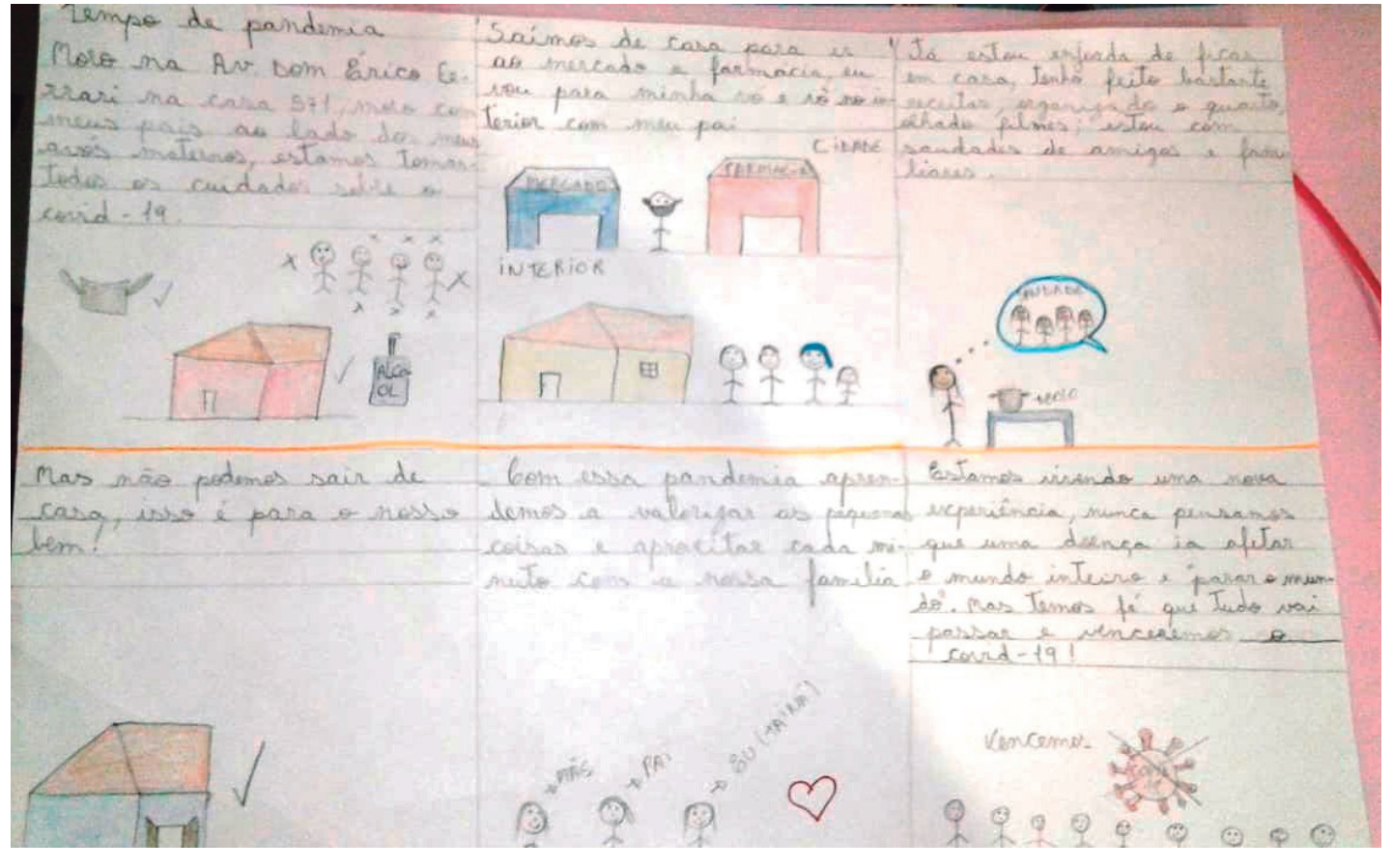

Fonte: HQ criada pelo aluno B.

De uma maneira geral, obteve-se um retorno satisfatório da atividade realizada pelos alunos, era uma atividade livre e de criação de artes com história em quadrinhos que é um recurso que os alunos gostam de trabalhar. Os educandos da escola têm mostrado um interesse em participar das aulas remotas. Ademais, os pais estão colaborando na aprendizagem dos alunos, participando e orientando os filhos e se interessando em contatar os professores. A pandemia tem mostrado que muitos pais se aproximaram da escola para poder manter os filhos estudando diariamente, mesmo que em casa. Quem não tem internet à escola fornece as atividades impressas e recebe as mesmas para avaliação.

É um momento delicado para educação existem muitos desafios para ser superados, principalmente a ausência do contato direto entre professor e aluno. Os professores ficam ansiosos por não poderem acompanham a construção do aprendizado dos alunos, assim como os alunos, muitas vezes não criam rotinas para o estudo diário, para retirar as dúvidas em meio virtual. Além disso, a interação fundamental na educação fica comprometida. Mas, com certeza, vê-se um empenho dos professores, escolas, de um modo geral, para manter o aprendizado. A angústia e a brusca ruptura das aulas presenciais é um sobro na rotina das escolas, porém é um aprendizado diário e que ficará para outros momentos está construção que aqui se inicia neste ano de 2020.

\section{CONSIDERAÇÕES}

A Geografia escolar caminha para o aprendizado do cotidiano, da realidade e do espaço. Esta ciência apresenta um mundo que cabe nas mãos (REGO, et al., 2000), ou seja, vários temas, conceitos 
e conteúdos que versam a disciplina e o conhecimento do alunado. Entre os conceitos, o de lugar é o que ganha uma dimensão expressiva na educação escolar, pois abre possibilidades de relacionar muitos pontos sociais aos geográficos.

O conceito de lugar refere-se ao espaço habitado, vivido e percebido, a experiência do entorno da casa, do bairro, da rua e do cotidiano, esvaziando as infinidades de relações possíveis como o meio ambiente, com a saúde, com a cultura, entre outra. Na educação básica este conceito é o ponto de partida dos estudos do $6^{\circ}$ ano do ensino fundamental.

Por isto, ligando o ensino de Geografia com o lugar e a realidade é importante trazer a tona a questão da Pandemia, que tem afetado tanto a sociedade mundial, inclusive a educação que se processa em atividades remotas e o fechamento das atividades presenciais escolares. Fazer os alunos compreender e permitir que eles exponham o seu ponto de vista e a sua compreensão do lugar nesta experiência é fundamental para se processar o encontro da Geografia com a realidade e com o ensino.

A Geografia não é uma disciplina de "decorebas" e de conceitos fechados ou prontos que não se conectam com o dia-a-dia, o meio ambiente e a sociedade, pelo contrário ela abarca todos esses nós e explora o que os alunos podem contribuir com seus conhecimentos. As práticas pedagógicas devem permitir a reflexão, o comprometimento do mundo com o local que se vive para voar ao global que se acredita (REGO, et al. 2000). Assim, a ciência escolar precisa ser fundamentada em metodologias ativas, especialmente, nestes tempos desafiadores de Covid-19, onde o ensino teve uma imensa transformação momentânea. E esta discussão impõe aos alunos pensar o local para entenderem o global, os acontecimentos exteriores aos olhos do alunado.

Neste ritmo, a prática pedagógica aqui apresenta procurou trabalhar o lugar e as experiências de vida na Pandemia dos alunos, a partir da construção de conceitos e de histórias em quadrinhos, deixando livre a criatividade no desenvolvimento das tarefas propostas. Foi uma prática rica em seus resultados, mesmo à distância se observou a participação dos alunos, e a exploração de detalhes dos alunos em descrever sua vida no lugar. Alguns itens foram visíveis nas histórias, entre elas: a rotina escolar remota, a higiene, a apreensão dos alunos por não poder sair de casa. No final, se observou ainda a mensagem otimista dos alunos, que nos impulsiona em pensar um novo futuro, pós-pandemia: um reinício da educação e da história humana.

\section{REFERÊNCIAS}

ALMEIDA, M. E. B. de. Educação à distância na internet: abordagens e contribuições dos ambientes digitais de aprendizagem. Educação e Pesquisa, São Paulo, v. 29 n. 2, jul./dez. 2003.

ARRUDA, E. P. EDUCAÇÃO REMOTA EMERGENCIAL: elementos para políticas públicas na educação brasileira em tempos de Covid-19. EmRede, v. 7, n. 1, p. 257-275, 2020. 
CALLAI, H. C. Estudar o lugar para compreender o mundo. In: CASTROGIOVANNI, A. C. (Org.).

Ensino de geografia: práticas e textualizações no cotidiano. Porto Alegre: Mediação, p. 72-112, 2000.

CASTELLAR, S. A alfabetização em Geografia. Espaços da Escola, Ijuí, v. 10, n. 37, p. 29-46, jul./set. 2000.

CHAHUÁN-JIMÉNEZ, K. Evaluacióncualitativa y gestióndelconocimiento. Educación y Educadores. Chia, v. 12, n. 3, p. 179-195, set./dez. 2009.

FREIRE, P. Pedagogia do oprimido. 6. ed. Rio de Janeiro: Paz e Terra, 1978.

FRANÇA FILHO, A. L. DE; ANTUNES, C. DE F.; COUTO, M. A. C. Alguns apontamentos para uma crítica da educação à distância $(E A D)$ na educação brasileira em tempos de pandemia. Revista Tamoios, São Gonçalo (RJ), ano 16, n. 1, Especial COVID-19, p. 16-31, maio 2020.

LIBANEO, J. C. Didática. 2. ed. São Paulo: Cortez, 2013.

KAERCHER, N. A. A Geografia é o nosso dia a dia. In: CASTROGIOVANI, A. C. et al. (Orgs.). Geografia em sala de aula: práticas e reflexões. Porto Alegre: Associaçãodos Geógrafos Brasileiros, 1998.

MELO, K. C.; MEDEIROS, A. F. de; SILVA, A. de A. Uma linguagem alternativa no ensino escolar: as histórias em quadrinhos na mediação do ensino e aprendizagem da geografia. Ateliê Geográfico Goiânia-GO, v. 7, n. 1, Abril/2013, p. 260-283.

MENDONÇA, M. J.; REIS, L. C. T. D. Histórias em quadrinhos: um campo recente da pesquisa em geografia sobre conflitos. Revista Geo UERJ, Rio de Janeiro, p. 98-119, 2015.

NEVES, P. D. M.; RUBIRA, F. G.; Histórias em quadrinhos na geografia escolar. Geografia, Ensino \& Pesquisa, v. 21, n. 3, p. 118-129, 2017.

OLIVEIRA, M.;RODRIGUES, E. O ensino do lugar: reflexões sobre o conceito de lugar na Geografia, Ateliê Geográfico - Goiânia-GO, v. 13, n. 3, dez/2018, p. 136-156.

RAMA, A. Os quadrinhos no ensino da geografia. In: BARBOSA, A. et al. Como usar as histórias em quadrinhos na sala de aula. 3. ed. São Paulo: Contexto, 2007. p. 87-104. 
REGO, N. et al. Um pouco do mundo cabe nas mãos: geografizando em educação o local e o global. Porto Alegre: Editora da UFRGS, 2003.

SANTANA FILHO, M. M. de. Educação geográfica, docência e o contexto da pandemia COVID-19. Revista Tamoios, São Gonçalo (RJ), ano 16, n. 1, Especial COVID-19. p. 3-15, maio 2020.

SANTOS, M. A natureza do espaço: técnica e tempo razão emoção.4. ed.SãoPaulo: Hucitec, 2009.

TUAN, Yi-Fu. Espaço e Lugar: a perspectiva da experiência: Difel, 1983. 